\title{
Culture as Fourth Pillar of Sustainable Development: Perspectives for Integration, Paradigms of Action
}

\author{
Francesca Sabatini ${ }^{1}$
}

\begin{abstract}
The paper explores the relationship between culture and sustainable development. In particular, it advocates the introduction of cultural sustainability as a fourth pillar of sustainable development. A first section explores the existing research on the topic, and focuses on the notion of culture itself and how it should be intended in the context of sustainable development. Then, the existing debate over culture's position among the three pillars of sustainable development is presented. In the second section, the issue of assessing sustainability in cultural policies is addressed. The proposed approach suggests the interconnection of economic, societal and artistic dimensions of evaluation, thus going beyond the instrumental view of culture which is common in the sustainability discourse. Culture-driven sustainable development is presented in the third section: policies concerning the use of tangible heritage, the development of cultural districts and participatory practices for the performing arts are analysed; their ability to combine artistic merit and positive impacts on the other dimensions of sustainable development is eventually assessed. Conclusively, cultural policies and practices prove able to generate sustainable growth at all levels, not least the creative and artistic one; as a consequence culture can be fully considered a fourth pillar of sustainable development.
\end{abstract}

\section{Introduction}

The discourse on culture has come a long way since the Hague Convention on the Protection of Cultural Property in the Event of Armed Conflict (UNESCO, 1954) that is, since the institutional acknowledgement of its value to mankind.

To this first act of recognition followed, a decade later, Baumol and Bowen's study (1966) on what they defined "the economic dilemma" of the performing arts: it laid the foundations of an academic and multidisciplinary perspective on culture. It was, more simply, the starting point of what became known as cultural economics.

Besides theoretical considerations on the shifting terminology concerning culture (ranging from cultural property to tangible or intangible cultural heritage, to cultural goods or products), the role of culture in society has constantly been renegotiated through its contamination with other branches of knowledge: from the development of cultural economics, to the interest in creative industries to, ultimately, the recent debate on the role of culture in sustainable development.

These combinations, nonetheless, have sometimes led to a misleading conception of culture's dependence over an external legitimisation: culture has subsequently been viewed as a tool - be it for achieving sustainability, economic outcomes, and the like while losing sight of its intangible and non-use values.

Far from advocating an art for art's sake approach to cultural studies, it seems nonetheless necessary to rethink the relationship between culture, economics and society, and more specifically between culture and sustainable development, which is the specific focus of the present paper. 
The ultimate recognition of interdependence between culture and sustainable development, which happened in 2015, highlighted the importance of culture in building a sustainable future (UN, 2015) without properly identifying culture as a fourth pillar alongside the social, environmental and economic pillars of sustainable development.

While the notion of culture encompasses all three meanings of sustainable development, the opposite is not exactly true: the symbolic values of culture cannot be reduced to emanations of the other three pillars. In response to these considerations, this paper was elaborated so as to provide a theoretical framework which allows to identify culture as fourth pillar of sustainable development.

In the first section, a definition of culture is reached in order to assess how culture should be intended in the context of sustainable development. Then, the existing debate over culture's position among the three pillars of sustainable development is presented and argued upon.

In the second section, the issue of assessing sustainability in the cultural sector is addressed. The proposed approach suggests the interconnection of economic, societal and artistic dimensions of evaluation, thus going beyond the instrumental view of culture which is common in the sustainability discourse.

Fieldwork on culture-driven sustainable development is presented in the third section: policies concerning the use of tangible heritage, participatory practices for the performing arts and the development of cultural districts are analysed; their ability to combine artistic merit and positive impacts on all dimensions of sustainable development is assessed and a taxonomy of policymaking aimed at cultural sustainable development is eventually drafted.

Conclusively, cultural policies and practices prove able to generate sustainable growth at all levels, not least the creative and artistic one; as a consequence culture can be fully considered a fourth pillar of sustainable development.

\section{Towards a (re)definition of culture}

Defining culture is as crucial as it is difficult, due to the intrinsic elusiveness of the concept. The first definition relevant to the purposes of this paper is the one provided by UNESCO, which, in its turn, is borrowed from Tylor (1871), who defined culture as that complex whole which includes knowledge, beliefs, arts, morals, laws, customs, and any other capabilities and habits acquired by [a human] as a member of society.

Culture is here approached from an anthropological perspective, which encompasses the entirety of knowledge shared by a society. This prevailing institutional view generated a dualism between heritage, an immutable set of human acquisitions, and culture in a more general and dynamic sense, an evolving and mutable concept which embraces the anthropologic view while being closer to the socioeconomic sense of the term.

The institutional conception will be included in much of the later elaborations: Raymond Williams (1986) identified three different meanings to the term: culture as spiritual development, as set of values and as works and intellectual activity. Williams' definition adds two further layers to the UNESCO definition: one "upward", a somewhat platonic layer defining culture as a state or process of human perfection (Williams, 1986), and a second, "downward" layer towards the socioeconomic meaning of the term. 
This socioeconomic meaning was more deeply understood by Adorno and Horkheimer (1944), in their study of the culture industry. The economic perspective was additionally widened by Throsby, the first to investigate the notion of cultural sustainable development (1995).

When applying to culture the criteria of sustainable development, Throsby refers to both the economic and anthropologic meaning of the term culture: "it encompasses both the idea of cultural development in its own right, according art and culture an independent and valued role in their own terms within society, and culture as a set of attitudes and practices that can be instrumental in supporting, constraining and/or contributing to economic and social development in the widest sense" (Throsby, 1995).

In 2011, ACTION IS1007, a study from the European Cooperation in Science and Technology (COST hereon) identified three possible roles of culture within sustainable development: Culture in, for and as sustainable development. The first role ("in") sees culture standing as a fourth autonomous pillar of sustainable development; the second, ("for") advocates a mediating role of culture between the three pillars; the third, ("as"), "defines culture as the necessary overall foundation and structure for achieving the aims of sustainable development'.

From the perspective of the study, if culture was to be intended in a narrow sense as "arts and creative activities", the position of culture as fourth pillar of sustainable development could loosen the relationship of culture to nature and broader societal issues. Hence conclusions are drawn that a 4 th pillar approach for culture cannot be the only way forward.

ACTION IS1007 thus implicitly contrasts Throsby by adopting a broad, anthropological conception of culture which, however, is subordinate to the other aspects of sustainable development - and, as such, doesn't have the independent, valued role within society advocated by Throsby. The paradox of this perspective lies in the fact that by adopting the broader meaning of the term it narrows the possibilities of integration of culture within sustainable development. In this perspective, in facts, only two implications would be left: that of culture intended as an all-encompassing, extremely vague concept, and that of culture as a mediating force, an instrumental tool bridging other goals.

Moreover, the assumption that culture is better intended in sustainability when interpreted in the broad, anthropologic sense, implies a twofold omission: on the one hand, it omits that the economic meaning of culture, in the form of artistic and creative outputs, is a manifestation of its anthropological meaning, as cultural goods are but a manifestation of fundamental human instances: in facts they "generally serve an aesthetic or expressive rather than a clearly utilitarian purpose" (Hirsch, 1972) and have a symbolic value which is high relative to its practical purpose (Scott, 2000). On the other hand, such economic outcomes of culture, either in the form of policy or of marketed cultural outputs (artefacts, performances, and the like), often tightly intertwine the artistic dimension to a socio-environmental vocation - where the latter does not eclipse the former, and vice-versa.

At a policy level, the dichotomy generated by the institutional view of heritage on the one hand, and the operational view of cultural industries on the other, generated rigidity of approaches: two separate spheres are identified, that of static preservation of heritage and that of indifference to, if not mistrust of, the cultural industries. It would be simplistic to imply that the cultural industries and the arts have no role to play in 
sustainable development: the anthropologic and socioeconomic views on culture need to be comprised in the notion of sustainable development, and suitable, multidimensional performance indicators need to be developed accordingly.

\section{Assessing Value}

Value assessment (or, in managerial terms, performance measurement) is a controversial issue within the cultural context per se, especially as the value of cultural products, related to ideas, symbols and dreams, is difficult to determine (Hadida, 2015), causing performance definition and measurement to be ambiguous; it is all the more so when this value assessment meets the indicators pertaining to other disciplines and social sciences, as are sustainability and economics.

Again, a question of framing and terminology arises: research boundaries for performance evaluation in the cultural context range from policy studies (namely Throsby, 1995) to studies on the creative industries (Hadida, 2015). There is disagreement on the choice of the performance dimensions to evaluate, as well as on the evaluation criteria. The confused adoption of a variety of indicators, the prevalence of economic standards for performance evaluation; the difficulties of cultural institutions in operating a delicate balancing act between the different dimensions of performance (Lampel, Lant, Shamsie, 2006): these elements have probably affected negatively the advocacy of culture as fourth pillar of sustainable development. An attempt can be made nonetheless to draw a theoretical framework out of this complicated scenario.

Bourdieu (1986) identified three different forms of capital: the economic, the social and the cultural capital, which find their correspondence in the three values of the arts: the instrumental, institutional, and intrinsic value (Holden, 2006). While the approach of the two sociologists identified a threefold partition which is suitably applicable to the arts sector, most of the research on the performance evaluation of the creative industries focuses on two dimensions only: the economic and the artistic ones (Hadida, 2015). Being easier to evaluate, economic indicators prevail, also on the part of those institutions which virtually placed artistic excellence at the top of their value hierarchy (Tubide and Laurin, 2009).

A different approach is possible, nonetheless, as shown again by Throsby and Hadida. The former, in facts, was the first to apply the dictates of sustainability to culture indicating a set of criteria against which to evaluate programs, policies and strategies: advancement of material and nonmaterial well-being, intergenerational equity and maintenance of cultural capital, equity within the present generations, recognition of interdependence. At a policy level sustainability is reached through the production of selfgenerating or self-perpetuating characteristics in systems (Throsby, 1995).

Hadida adds a third dimension to cultural industries' performance evaluation, seldom taken in consideration but fundamental in the sustainability discourse: societal impact, also defined as environmental sustainability ${ }^{1}$. In the final section of her study, Hadida

1 The notion of environmental sustainability in cultural industries should not be misunderstood for the meaning it has in the common sustainability discourse. The equation of environmental sustainability and societal impact suggests a different interpretation of the term, bearing reference to the cultural industry's embeddedness within the outer social environment. 
analysed the patterns of inter-connectedness between the different dimensions of performance evaluation. What emerged is that not only artistic merit and commercial performance are often conflicting dimensions, but that societal impact (that is, cultural outputs' direct contribution to sustainability) is, on the contrary, often complementary to artistic merit.

Almost a century earlier, this conflicting relation had been highlighted by Adorno, Benjiamin, Horkheimer, who define the cultural industries as detached from economic laws, and having everything to lose from confronting them (Hadida, 2015). In $2005 \mathrm{~J}$. Craik had proposed the substitution of societal indicators to the economic ones. Rentschler and Potter (1996), on the contrary, illustrated the potential connection between commercial performance and societal impact of cultural institutions: their most challenging study proves how in nine Australian non-profit museums the societal mission was best served by commercial means.

However controversial, these findings the many possible interconnections between different aspects of performance in the cultural sector. Adding the societal impact dimension of performance might then contribute to the advocacy of culture as fourth pillar of sustainable development, while deepening the understanding of value assessment in the creative industries and its multi-layered dimensions.

Conclusively, cultural policies and creative industries prove not to have the selfreferential role the ACTION IS1007 study claimed them to have. Rather contrarily, they have the potential for playing an active role in fostering sustainability, while having explicitly marketed creative outputs.

\section{Perspectives for Integration: Cultural Activities and Sustainability}

The present section considers three possible actions in the field of cultural industries and cultural policies. The actions taken in consideration are, first, policies aimed at the use of built heritage; second, participatory practices for the performing arts; third, the development of cultural districts.

\subsection{Built heritage}

Cultural heritage has recently widened its interpretative range: it encompasses ancient temples as well as dismissed industrial buildings, thus challenging the notion of heritage itself and its value to society: the process of identifying cultural heritage has hence moved along two different paths, heritage by designation and heritage by appropriation (Rautenberg, 1998), the first being an institutional action, the second an informal process of collective preference.

Together with the definition of cultural heritage, also its uses have been reframed: new creative practices and new possibilities for interaction have emerged. Trimarchi (2004) explores the vertical integration between cultural heritage and the performed arts. Artistic merit is pursued through the generation of mixed cultural stock, commercial performance is fostered by the audience's higher willingness to pay for the joint consumption of the heritage site and the performance.

In addition, this production of culture by means of culture generates societal impact: it benefits present generations by increasing accessibility; through active preservation it also 
ensures the transmission of cultural heritage to future generations (intergenerational equity); finally, since physical capital does not decrease and intellectual capital increases, the total level of social welfare increases through time (Trimarchi 2004).

Tweed and Sutherland (2007) explore the relationship between cultural heritage and sustainable urban development, advocating that cultural heritage contributes to the well being of different social groups living in cosmopolitan urban environments: here, the economic dimension of cultural heritage is left out in favour of the artistic merit of cultural heritage, which expresses fundamental symbolic values for communities; it is on the basis of such values that societal impact is assessed. The surveys conducted in the study in different European cities illustrated how heritage was perceived as an important component in people's quality of life and their satisfaction of immaterial needs of belonging and creativity. From this perspective, built heritage contributes directly to the $11^{\text {th }}$ goal of sustainable development, "sustainable cities and communities".

Ulibarri and Ulibarri (2009) estimated the economic value of a cultural heritage site, by conducting an analysis on the impact of built heritage (the Petroglyph National Monument in Australia) on tourism and local development. The commercial performance of the site was assessed through willingness to pay (WTP) of both tourists and locals for, respectively, using and preserving the heritage site. WTP was thus used to assess the economic value of the site, i.e. its commercial performance.

Indirectly, however, WTP also illustrated the site's value to local Aboriginal people and its ability to foster local development: as a consequence, the sustainable socio-economic growth of indigenous people, explicitly dealt with in the Sustainable Development Goals, is positively impacted by the regulated touristic exploitation of built heritage, according to the principle of equity within present generations and inter-generational equity.

\subsection{Performing arts}

A curious knowledge gap exists between practice and research in the field of participatory practices for the performing arts. From a theoretical point of view, little attention is paid to the socioeconomic implications of such creative actions; as a consequence, only few case studies provide a practical basis to such research. This is all the more true from a sustainability research perspective, which, as said earlier, only puts a stress on specific social outcomes of community art projects, extruding their commercial performance and/or their artistic merit.

A variety of actors, however, are exploring the possibilities of audience participation. Among them it is possible to distinguish institutions which feature audience participation as their core activity, and institutions which develop participatory projects alongside their usual stream of cultural production.

The Mahogany Opera Group (U.K.), La Fabrique Opéra (France), the Upper Šančia Community Association (Lituania) are but a few of the cultural organisations whose business model is centred on participatory practices: their value proposition consists not just of the delivery of a high-quality artistic product but also of active audience involvement in the realisation of such products. From an economic point of view, their activity redefines the notion itself of experiential good, shaping a new level of involvement in the production and fruition of culture.

A higher degree of audience participation is among the fundamental components of 
contemporary audience development strategies in most theatres. However, a limited number of institutions is pushing the involvement further, as is the case of Teatro Massimo in Palermo and its "Elisir di Danisinni".2

Danisinni is a disadvantaged neighbourhood in Palermo which became the main location of the theatre's opera project, which resulted in the staging of a reinvented Elisir d'Amore (Donizetti) performed for free in the open air. The project ran in the neighbourhood for a whole year: orchestra rehearsals were held in dismissed buildings partially regenerated to host the theatre's activities, and the local inhabitants of Danisinni was involved as the chorus.

Urban regeneration and local community involvement were crucial aspects of the production, and serve as indicators of societal aspects. However, a critical issue of public funding arises, since the Italian funding board for the performing arts does not take free performances into account when assigning grants: the funding system does not allow for the self-perpetuating characteristic of culturally sustainable policies identified by Throsby.

In conclusion, the site-specificity of the performances, the inter-generational cooperation they foster, and the access to culture and education that they imply are clear indicators of their societal impact. Borrowing terms from the business vocabulary, it could also be hinted that the institutions' brand image is benefitted by the social responsibility implied in the project itself. Most of the activities have a very low financial output: on the contrary, artistic merit and societal impact are tightly interconnected.

\subsection{Cultural districts}

The notion of district first appeared in economic research in Marshall (1890), but the tie between cultural districts and sustainable development was mainly explored by Santagata (2006), who classified cultural districts as industrial (producing positive externalities, featuring localised culture), and institutional (involving property rights and symbolic values). Whatever the class they fall into, cultural districts are characterised by the transmission of tacit knowledge and the production of cultural capital in the form of cultural goods. From an economic point of view, districts are characterised by a high and quick diffusion of knowledge, often resulting from spillovers, the intense creation of creative externalities, innovation and widespread networking.

Santagata defines cultural goods as "idiosyncratic", thus having specific characteristics depending on their specific context of production. Cultural goods, in facts, are produced by firms which are intensely integrated within the territory and the local community; he also reasserts the fundamental coexistence, within the cultural artefact produced by a cultural district, of tangible and intangible features, in reason of which they cannot be reduced to mere object nor to mere symbol.

Cultural districts' contribution to sustainable growth is extensive and explicit, in that they embed all aspects of sustainability, not least the cultural one: the three dimensions of evaluation are here more interconnected than in any other realm of the cultural field. The artistic merit and commercial performance of cultural districts, expressed in the

2 The information of this case study was kindly provided by the Superintendent of Teatro Massimo, Francesco Giambrone, during an interview to the author. 
production of cultural goods which have both a use- value and an intrinsically artistic one, are sided by societal impact, expressed in the transmission of localised culture and production of cultural capital.

In addition, environmental sustainability is ensured by sustainable modes of production and a sustainable relationship to the environment, which is a crucial element of the tacit knowledge transmitted in the district (as was also pointed out in ACTION IS1007). In conclusion, inter-generational equity, equity within the present generation, and the advancement of material and non-material well-being are aspects of sustainability which are well-represented and interdependent within districts.

\subsection{Paradigms of action: arts, engagement and sustainability}

The continuous evolution of the cultural industries make them hard to define, evaluate, and integrate in the sustainability framework. Rather than eluding this challenge, however, adequate policies need to regulate, enable and empower the role of cultural industries in building a sustainable growth. Acknowledging complexity, adopting flexible approaches and integrating different perspectives must be the principles underpinning this challenge; in order to do so, a balancing act (Lampel et al., 2006), between preservation and innovation, between artistic merit, societal impact commercial performance is to be reached. A taxonomy of policy interventions can be subsequently traced for each of the cultural actions presented in this section.

Built heritage: if properly regulated, the use of cultural heritage for live performances can limit, or even avoid, the risk of extinction of built heritage. A certain degree of regulation is, then, obviously needed in other to avoid the intensive exploitation of heritage infrastructures; however, policies too often opt for a rigid approach of total preservation, limiting the beneficial effects of vertical integration. A balance needs to be found between a hard regulation for preserving the physical stock of cultural heritage, and a soft regulation of its use as input for the production of new cultural values.

Performing arts: cooperation should be fostered between old and new actors in the field, e.g. between NPOs and theatres, in order to favour synergy between institutions and with communities; policies should reframe the eligibility criteria for funding in order to valorise socially-oriented projects and provide support to activities with high societal impact but low financial sustainability.

Cultural districts: while supervising the preservation of cultural practices embedded in the production processes of the district, for example through the attribution of collective property rights (Santagata, 2006), policies should seek a certain degree of deregulation and provide incentives for new local firms in the district, in order to foster the emergence of creativity and knowledge spillovers able to generate new financial and cultural capital.

\section{Conclusions}

This paper has attempted at providing an organic theoretical framework for investigating the role of culture in sustainable development.

The rigidity of the conventional institutional view, opposed to a more holistic and fluid conception of culture, has a twofold consequence: first, a form of cultural utilitarianism, 
which deprives culture of its highly symbolic and often artistic value, and reduces it to a subordinate toolbox of other value systems within the sustainability logic; second, a threshold to the definition of culture which rises a barrier to entry to the cultural actors producing sustainable impact on society and the environment which is not acknowledged for, due to inadequate categories.

The complex relationship between symbolic values, material uses, socio-anthropologic as well as economic implications in cultural outputs cannot be reduced to emanations of, or tools for, the reaching of sustainable goals. On the contrary, the notion of culture can prove useful in the sustainability discourse only when plunged in the reality of material cultural outputs.

For this reason, a more thoughtful understanding of the notion itself is necessary: the taxonomy elaborated in the first section illustrates how broadening the meaning of culture results in narrowing its scope: to intend it as a set of values on which sustainable development is based equals reducing cultural policies and actions to instrumental tools with no cultural value whatsoever. The most appropriate definition of the term accounts for both the anthropologic and the socio-economic meaning of culture.

The assessment method outlined in the second section tries to combine sustainability criteria and performance dimensions of the cultural sector within a holistic approach of evaluation: the criteria of culturally sustainable development (Throsby, 1995) are identified for the assessment of cultural policies; as the cultural industries, three main dimensions of performance evaluation are identified (Hadida, 2015): commercial performance, artistic merit and societal impact. The studies presented illustrate the fundamental inter-connectedness of the three dimensions: not only cultural industries are not narrowing the scope to culture's contribution to sustainable development: sustainability is often enabled and fostered by both artistic merit (LeBlanc, 2010) and commercial performance (Rentschler and Potter, 1996) of the cultural sector.

The three culture-oriented practices illustrated in the third section exemplify this theoretical framework: while specifically aiming at the production of material and immaterial cultural outputs, the examples show how cultural activities produce sustainable impacts from a social, economic and environmental point of view: Accordingly, the combination of artistic, commercial and societal impacts in their evaluation prove more effective than it would be to evaluate them in the light of sustainable development only, as their cultural value is accounted for without extruding any aspect of sustainability.

In conclusion, human communities' cultural instances, either expressed through objects, practices or buildings, cannot be entirely comprised in other value system - such as the social or the economic. Consequently, culturally sustainable development is the only notion properly able to encompass all the meanings of culture and all its complex interactions with the social, economic and environmental dimensions of human life. Culture has been relegated in a utilitarian position with respect to the other pillars of sustainability: further research should focus on the interconnectedness of performance dimensions of the cultural sector, but also on the many possible interaction of culture itself, of cultural economics and sustainable development. Rather than just enabling sustainable development through culture, efforts should be put on enabling the sustainable development of culture itself. 


\section{References}

Battaglini E., Soini K., Birkeland I., Duxbury N, Fairclough G., Horlings L., and Dessein J.(2015)., Culture in, for and as sustainable development: conclusions from the COST Action IS1007 investigating cultural sustainability, Dessein J., Soini K., Fairclough G. and Horlings L. (ed.), University of Jyväskylä.

Baumol J. W., Bowen G (1966), Performing arts, the economic dilemma: a study of problems common to theatre, opera, music and dance, New York: Twentieth Century Fund.

Bourdieu A (1986), The forms of capital, in J. Richardson (ed.), Handbook Theory and research for the sociology of education, New York: Greenwood.

Craik J. (2005), Dilemmas in public support for the arts and cultural sector, Australian Journal of Public Administration, 64:4.

LeBlanc A. (2010), Cultural districts, a new strategy for regional development? The south-east cultural district in Siciliy, Regional Studies, 44:7.

Hadida A. L. (2015), Performance in the creative industries, in The Oxford Handbook of Creative Industries, Jones C., Lorenzen M., Sapsed J. (ed.) Oxford: Oxford University Press.

Hirsch P. (1972), Processing fads and fashion. An organization set analysis of cultural industry systems, American Journal of Sociology, 77.

Holden J. (2004), Capturing cultural value: how culture has become a tool of government policy, London, UK: Demos.

Horkheimer, M., Adorno, T. (1974), La production industrielle des biens culturels, dialectique de la raison, Paris: Gallimard (1st ed. 1944).

Lampel J., Shamsie J., Lant T. K. (2000), Balancing act. Learning from organizing practices in cultural industries, Organization Science, 11:3.

Rautenberg M. (1998), L'émergence patrimoniale de l'ethnologie entre mémoire et politiques publiques. In: Poulot, D. (Ed.), Patrimoine et modernité, Paris: L'Harmattan.

Rentschler R. and Potter B. (1996), Accountability versus artistic development: the case for non-profit museums and performing arts organizations. Accounting, Auditing and Accountability Journal, 9:5.

Santagata W. (2006), Cultural districts and their role in developed and developing countries, in Handbook of the Economics of Art and Culture, by Ginsburgh A. and Throsby D. (ed.), Elsevier.

Sutherland M., Tweed C. (2007), Built cultural heritage and sustainable urban development, Landscape and Urban Planning, 83:1.

Scott, A. J. (2000), Capitalism, cities, and the production of symbolic forms, Transactions of the Institute of British Geographers, 26:1.

Throsby D. (1995), Culture, economics and sustainability, Journal of Cultural Economics, 19:3.

Trimarchi M. (2005), Regulation, integration and sustainability, International Journal of Heritage Studies, 10:5.

Turbide J., Laurin C. (2009), Performance measurement in the arts sector: the case of the performing arts, International Journal of Arts Management, 11:2.

Ulibarri C. A. and Ulibarri V. C. (2009), Benefit-transfer valuation of a cultural heritage site: the Petroglyph National Monument, Environmental and Development Economics, 15.

Williams R. (1986), Keywords: a vocabulary of culture and society, Fourth Estate Ltd.

Convention for the protection of cultural property in the case of armed conflict, UNESCO 1954.

Culture: a driver and enabler of sustainable development, UNESCO Thematic Think Piece, 2012.

United Nations Sustainable Development Summit, UN, 2015.

Culture in the sustainable development goals: a guide for local action, United Cities and Local Governments (UCLG), 2018. 